\title{
Impact of Environmental Factors on the Photosynthesis and Respiration of Young Seedlings of Sargassum thunbergii (Sargassaceae, Phaeophyta)
}

\author{
Zhourui Liang, Xiutao Sun, Feijiu Wang*, Wenjun Wang, Fuli Liu
}

Key Laboratory of Sustainable Development of Marine Fisheries, Ministry of Agriculture, Yellow Sea Fisheries Research Institute, Chinese Academy of Fishery Sciences, Qingdao, China.

Email: *wangfj@ysfri.ac.cn

Received October $9^{\text {th }}, 2013$; revised November $19^{\text {th }}, 2013$; accepted December $3^{\text {rd }}, 2013$

Copyright (C) 2013 Zhourui Liang et al. This is an open access article distributed under the Creative Commons Attribution License, which permits unrestricted use, distribution, and reproduction in any medium, provided the original work is properly cited.

\begin{abstract}
Sargassum thunbergii is of great economic and ecological value to sea cucumber cultures and seaweed beds. However, studies on photosynthesis and respiration of $S$. thunbergii are limited. In this study, a liquid-phase oxygen electrode system and a chlorophyll fluorescence spectrometer were used to determine the photosynthetic characteristics of $S$. thunbergii seedlings at various light intensities, temperatures, and salinities. The light-saturated net photosynthetic rates, light saturation points, and respiratory rates of germlings were investigated. Results showed that the increase in rate of light saturation point was slow in the first $4 \mathrm{~d}$, rapidly increased from $5 \mathrm{~d}$ to $9 \mathrm{~d}$, and then gently increased at the final few days of the $15 \mathrm{~d}$ indoor culture period. The photosynthetic rate or respiratory rate of the seedlings rapidly and significantly decreased when the temperature was $<10^{\circ} \mathrm{C}$ or $>28^{\circ} \mathrm{C}$. Short-term high- or low-salinity shock had significant effect on the photosynthetic and respiratory rates of the seedlings, specifically at 10 and 50 psu. However, the photosynthetic and respiratory rates recovered to the normal levels after $24 \mathrm{~h}$ of recovery period, which demonstrated a powerful ion-transport system of the seedlings. These results provided reference for the artificial breeding of $S$. thunbergii.
\end{abstract}

Keywords: Sargassum Thunbergii; Temperature; Salinity; Light; Photosynthesis; Respiration

\section{Introduction}

Sargassum thunbergii of the Sargassaceae (Phaeophyta) family is a warm water marine brown alga that is commonly found in rocky intertidal zone along the Northwestern Pacific Ocean, inhabiting the coast of China (from northern Liaodong peninsula to southern Leizhou peninsula), Russia (in southern Kurile islands and Sakhalin island), Japan (from Hokkaido to Ryukyu islands), and Korea. S. thunbergii can form extensive seaweed beds, which serve as the spawning, nursery, and feeding ground for fish, shellfish, and other marine organisms [1]. $S$. thunbergii has the potential application in medicine and mariculture, as well as in chemical and food industries [2-4]. It is also used as an important source of feed for cultured sea cucumber Apostichopus japonicus, which has become a huge industry in China over the last 10 years [5]. The increasing demand for $S$. thunbergii has resulted in the depletion of natural stock along the north-

${ }^{*}$ Corresponding author. ern coast of China. Hence, large-scale mariculture and artificial breeding of $S$. thunbergii is urgently needed. However, availability of a large quantity of seedlings is a bottleneck for successful large-scale farming [6].

Studies on the ecology [7-9], population genetic structure [10-13], and cultivation [6,14-17] of S. thunbergii have been conducted recently. However, the photosynthetic physiology of $S$. thunbergii is poorly understood. Comparative studies on photosynthesis in various parts of $S$. thunbergii were conducted $[18,19]$, as well as some preliminary studies on the impact of environmental factors, such as nutrients and current speed, on the photosynthesis of S. thunbergii in 1980s and 1990s [20-23]. Preliminary studies on stress physiology of S. thunbergii were performed in the last few years [24-26]. Inhabiting the intertidal zone, $S$. thunbergii is regularly exposed for $2 \mathrm{~h}$ to $3 \mathrm{~h}$ daily between low and high tides, during which the seaweed is exposed to direct solar irradiance, possible rainfall, desiccation, and dramatic changes in tempera- 
ture. The alga has shown some mechanisms to adapt to the drastic environmental changes, thereby maintaining photosynthesis and growth.

Among the factors that regulate the photosynthesis among seaweeds, irradiance, temperature, and salinity are the most important [27]. Therefore, determining the effects of various light intensities, temperatures, and salinities on photosynthetic characteristics is necessary so as to find the optimum cultivation conditions for $S$. thunbergii.

Before being developed into upright thalli, young seedlings of $S$. thunbergii are small and they face severe competition from various undesirable epiphytic algae and invertebrate larvae in the sea. These organisms compete with the young seedlings for nutrients, substrate space, light, and other resources. During the culture of Hizikia fusiformise and Sargassum horneri, immersion in freshwater and desiccation of culture rope can be used to remove harmful species, such as Ectocarpus spp. and Polysiphonia spp., which are sensitive to osmotic changes [28, 29]. This method can also be used to eliminate organisms that are harmful for cultured $S$. thunbergii $[15,30]$, if the range of osmotic change that is tolerable for $S$. thunbergii is determined. Hence, studying the tolerance of young seedlings to changes in salinity supports the mass production of $S$. thunbergii.

In the present study, the liquid-phase oxygen measurement system and chlorophyll fluorescence spectrometer were used to measure photosynthetic characteristics of growing seedlings under various light intensities, temperatures, and salinities. The present study aims to provide reference in optimizing environmental conditions for $S$. thunbergii seedling rearing.

\section{Materials and Methods}

\subsection{Material and Culture Conditions}

Parental male and female plants with well-developed receptacles were obtained from an intertidal zone in Taiping Bay $\left(36^{\circ} 05^{\prime} \mathrm{N}, 120^{\circ} 35^{\prime} \mathrm{E}\right)$, Qingdao, China on 20 July 2011. S. thunbergii was usually found in the lower areas of the rocks and was closely adhering to the substrate. Sample collection was done manually with the help of knife or scalpel during the low tide. The samples were sealed in a plastic bag with some seawater and transported to the laboratory within $3 \mathrm{~h}$ in an insulated cooler $\left(5^{\circ} \mathrm{C}\right)$. The samples were cleaned of visible epiphytes and attached sediments and maintained in a glass aquarium filled with filtered natural seawater $(33 \mathrm{psu})$ at $20^{\circ} \mathrm{C}$ with supplements of $\mathrm{NO}_{3}^{-}-\mathrm{N}$ and $\mathrm{PO}_{4}^{3-}-\mathrm{P}$ at 3 and $0.3 \mathrm{~g} \cdot \mathrm{m}^{-3}$, respectively. Illumination at $100 \mu \mathrm{mol}$ photons $\mathrm{m}^{-2} \cdot \mathrm{s}^{-1}$ was applied using fluorescent tubes $(12 \mathrm{~h}: 12 \mathrm{~h}=$ light:dark). In addition, a supplement of $2 \mathrm{~g} \cdot \mathrm{m}^{-3}$ germa- nium dioxide was added to the seawater to inhibit diatom growth. The seawater was aerated vigorously and renewed by $50 \%$ every other day.

Photosynthetic rates were measured in terms of oxygen evolution using a Clark-type oxygen electrode (Hansatech Oxygraph, England, UK). The light was provided using a halogen lamp. An illuminometer (HANNA, Italy) was used to measure the light intensity, and the temperature was maintained constantly using a cooling circulator (F12-ED Refrigerated/Heating Circulator, Germany). Zero oxygen was employed in the oxygen electrode chamber with $\mathrm{Na}_{2} \mathrm{~S}_{2} \mathrm{O}_{4}$.

\subsection{Light Test}

Germlings were collected and seeded into the beakers. A $2 \mathrm{~mL}$ aliquot of the cell solution, which contained germlings, was transferred to the oxygen electrode chamber, which was magnetically stirred at a speed of $100 \mathrm{r} \cdot \mathrm{min}^{-1}$. Approximately $200 \mu \mathrm{L}$ of algal solution was removed from the oxygen electrode chamber at a rotor-stirred condition for microscopic counting and length measurements. The number of germlings was controlled at approximately 1000 individuals in the chamber.

Photosynthetic rates $(\mathrm{PN})$ and respiratory rates (RR) were measured at $21^{\circ} \mathrm{C}$. The light transmittance of the chamber wall was measured to calibrate the light intensity. The samples were conditioned at certain light intensity for approximately $60 \mathrm{~min}$ to achieve stability before measurement. Each measurement was accomplished within $10 \mathrm{~min}$, and the linear oxygen evolution versus time was recorded. The length, light-saturated PN (PNsat) as well as its corresponding light intensity, namely, light saturation point (LSP), and RR of the germlings were measured daily between days 1 and 7 and at days 9, 12, and 15. The data were converted to the quantity of oxygen release for 1000 germlings per unit time. Three measurements were performed each time and the average values of readings were obtained.

\subsection{Temperature Test}

Intact seedlings $(1.5 \mathrm{~mm}$ to $2.5 \mathrm{~mm})$ were pre-cultured with filtered natural seawater $(33 \mathrm{psu})$ at $20^{\circ} \mathrm{C}$ in temperature-controlled photoincubator (Jiangnan, Co. Ltd., China) at an irradiance of $200 \mu \mathrm{mol}$ photons $\mathrm{m}^{-2} \cdot \mathrm{s}^{-1}(12$ $\mathrm{h}: 12 \mathrm{~h}=$ light:dark) for approximately one week. Prior to the experiments, approximately $0.1 \mathrm{~g}$ of the seedlings was placed equally into each beaker with $800 \mathrm{~mL}$ of culture solution. The culture solution was composed of filtered natural seawater enriched with $\mathrm{NO}_{3}^{-}-\mathrm{N}$ and $\mathrm{PO}_{4}^{3-}-\mathrm{P}$ at 3 and $0.3 \mathrm{~g} \cdot \mathrm{m}^{-3}$, respectively.

The seedlings were incubated at 10, 15, 20 (control group), $25^{\circ} \mathrm{C}, 28^{\circ} \mathrm{C}$, and $31^{\circ} \mathrm{C}$ in the incubators for $6 \mathrm{~h}$ 
under the same light conditions as described above. Approximately $0.014 \mathrm{~g}$ of the seedlings was transferred from the incubator to the oxygen electrode chamber hourly to measure $\mathrm{PN}$ at the experimental temperatures under irradiance of $200 \mu \mathrm{mol}$ photons $\mathrm{m}^{-2} \cdot \mathrm{s}^{-1}$. RR was also measured in the dark at the experimental temperatures. Three measurements were performed each time and the average values of the readings were obtained.

\subsection{Salinity Test}

Intact seedlings ( $1.5 \mathrm{~mm}$ to $2.5 \mathrm{~mm}$ ) were exposed to salinity treatments at 10, 20,33 (control group), 40 , and 50 psu for $6 \mathrm{~h}$ at $20^{\circ} \mathrm{C}$ in a photoincubator under irradiance of $200 \mu \mathrm{mol}$ photons $\mathrm{m}^{-2} \cdot \mathrm{s}^{-1}$. Approximately $0.014 \mathrm{~g}$ of seedlings was transferred from the incubator to the oxygen electrode chamber hourly to measure PN at the experimental salinities. RR was also measured in the dark using the same method. Besides the oxygen electrode test, a chlorophyll fluorescence spectrometer (DIVING-PAM, WALZ, Germany) was used to measure $F_{v} / F_{m}$ at the experimental salinities. $F_{v} / F_{m}$ reflect the potential quantum efficiency of photosystem II and are used as a sensitive indicator of plant photosynthetic performance [31]. Among the indicators obtained through performing chlorophyll fluorescence measurements, $F_{v} / F_{m}$ is used most frequently. $F_{v} / F_{m}$ is determined from the easiest and simplest type of chlorophyll fluorescence measurement [32]. The $F_{v} / F_{m}$ of the young seedlings was measured hourly after a $1 \mathrm{~h}$ dark-adapted state at the experimental salinities. After the $6 \mathrm{~h}$ treatment and $24 \mathrm{~h}$ recovery (12 $\mathrm{h}: 12 \mathrm{~h}=$ light: dark) in normal seawater (33 psu), PN, RR, and $F_{v} / F_{m}$ were measured. Three measurements were performed each time and the average values of the readings were obtained.

\subsection{Statistics}

The data were expressed as means \pm standard deviation. Two-way ANOVA was used to compare the treatments, and multiple comparisons were performed with the Student-Newman-Keuls method. The $t$-test was used to compare the control and treatments at each time point. The significance level was set at 0.05 .

\section{Results}

\subsection{Light Test}

As shown in Figures 1 and 2, PNsat, LSP, and RR of germlings gradually increased with the increase in length within $15 \mathrm{~d}$. The increase in PNsat, LSP, and RR was slow in the initial $4 \mathrm{~d}$, rapidly increased from $5 \mathrm{~d}$ to $9 \mathrm{~d}$, and then gently increased at the final few days.

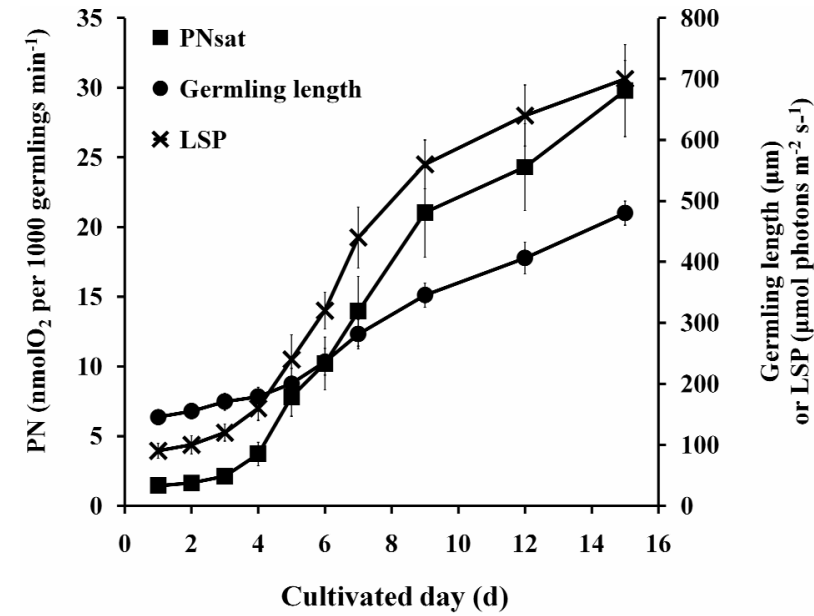

Figure 1. PNsat and LSP of germlings at prolonged culture time.

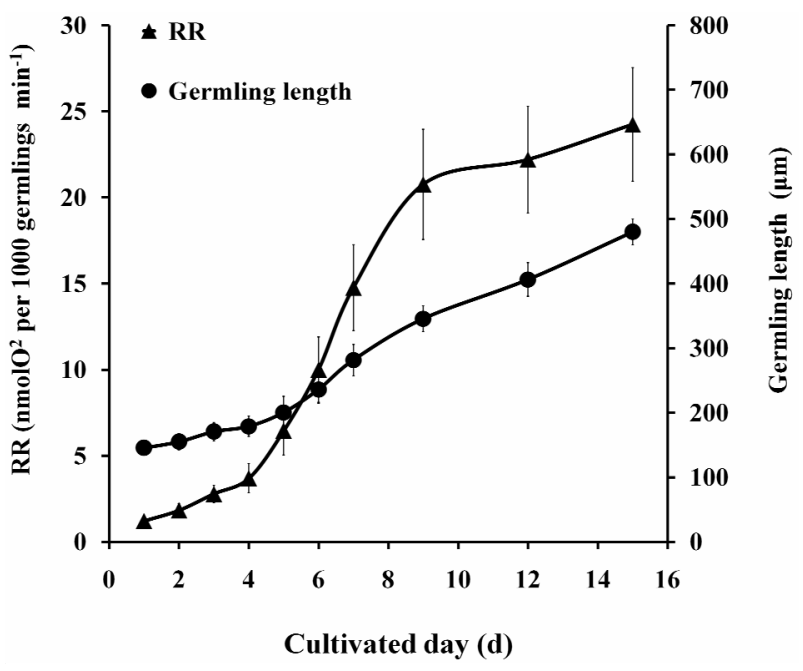

Figure 2. RR of germlings at prolonged culture time.

\subsection{Temperature Test}

Two-way ANOVA showed that PN was significantly ( $P$ $<0.05$ ) affected by temperature (Figure 3). Multiple comparisons indicated no significant difference $(P>0.05)$ between $\mathrm{PN}$ at $20^{\circ} \mathrm{C}$ and $25^{\circ} \mathrm{C}$ treatments; however, the $\mathrm{PN}$ values at these temperature treatments were both significantly different from those of the other treatments $(P$ $<0.05$ ). $\mathrm{PN}$ at $10^{\circ} \mathrm{C}$ and $31^{\circ} \mathrm{C}$ were both drastically reduced throughout the stress treatment.

The results of two-way ANOVA showed that RR was significantly $(P<0.05)$ affected by temperature or culture time (Figure 4). Multiple comparisons showed that no significant difference was found $(P<0.05)$ in RR among $10^{\circ} \mathrm{C}, 15^{\circ} \mathrm{C}, 20^{\circ} \mathrm{C}$, and $25^{\circ} \mathrm{C}$ treatments; however, the $\mathrm{RR}$ values at these temperature treatments were significantly different from those at $28^{\circ} \mathrm{C}$ and $31^{\circ} \mathrm{C}$ treatments $(P<0.05)$. 


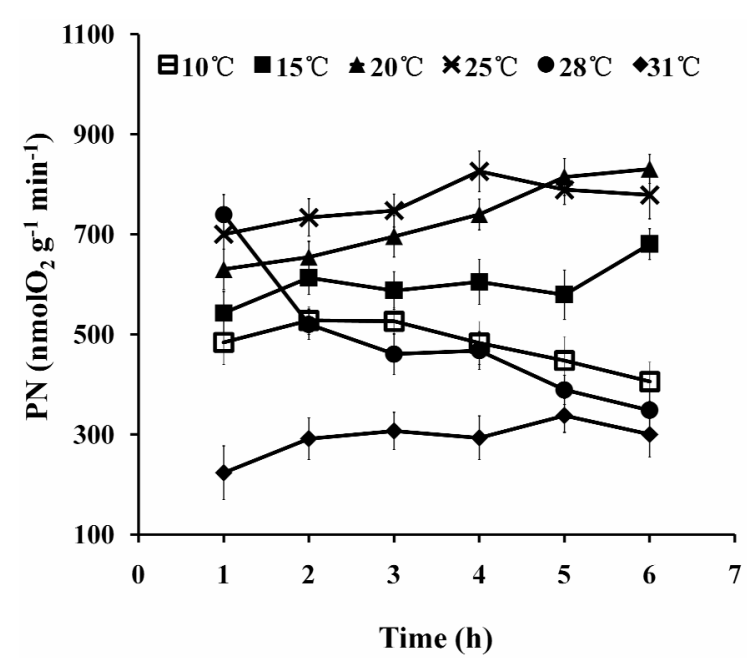

Figure 3. PN of seedlings treated at various temperatures for up to $6 h$.

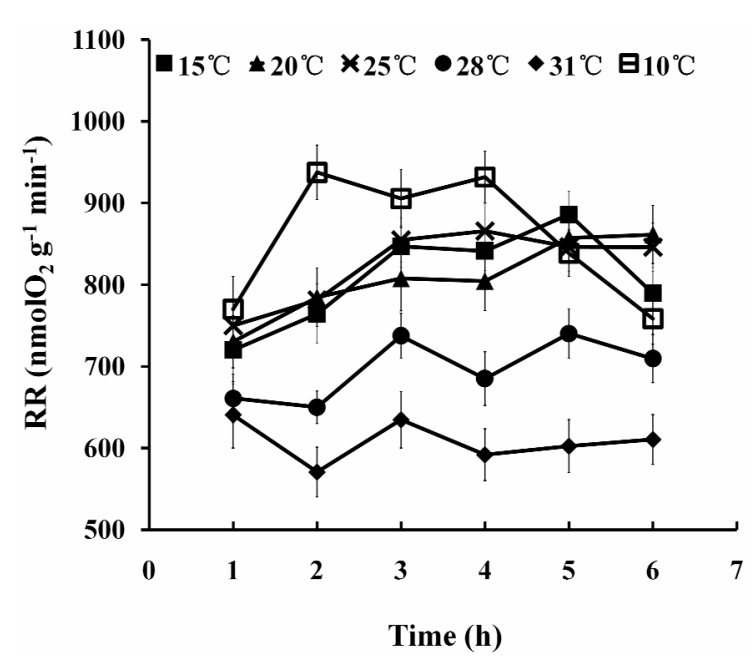

Figure 4. RR of seedlings treated at various temperatures for up to $6 \mathrm{~h}$.

\subsection{Salinity Test}

Two-way ANOVA showed PN and $F_{v} / F_{m}$ were both significantly $(P<0.05)$ affected by salinity (Figures 5 and 6). Multiple comparisons showed significant difference $(P<0.05)$ in $\mathrm{PN}$ or $F_{v} / F_{m}$ between $33 \mathrm{psu}$ and other treatments. No significant difference was found $(P$ $>0.05)$ in $\mathrm{PN}$ or $F_{v} / F_{m}$ between 10 and 50 psu treatments or between 20 and 40 psu treatments. The $t$-test showed that $\mathrm{PN}$ or $F_{\mathrm{v}} / F_{\mathrm{m}}$ at 10 and 50 psu was remarkably decreased $(P<0.05)$ compared with that of the control (33 psu).

Two-way ANOVA showed that RR was significantly affected $(P<0.05)$ by both high and low salinities (Figure 7). Multiple comparisons showed no significant difference $(P>0.05)$ between the 10 and 50 psu treatments, but they were both significantly different $(P<0.05)$ from other treatments. PN of 40 psu treatment was greater than that of the control within $1 \mathrm{~h}$ of treatment.

PN, RR, and $F_{v} / F_{m}$ (Figure 8) of the seedlings treated with different salinities for $6 \mathrm{~h}$ recovered to the normal level after a $24 \mathrm{~h}$, which showed no significant $(P>$ $0.05)$ difference compared with that of the control group (33 psu).

\section{Discussion}

PNsat, LSP, and RR of germlings at different lengths were investigated to determine the optimum light control for seedling rearing. Photosynthetic rate is important in assessing the ability of plants to absorb carbon dioxide. LSP describes the amount of light that is beyond the capability of the chloroplast to absorb carbon dioxide. Photosynthesis is initiated by the absorption of light en-

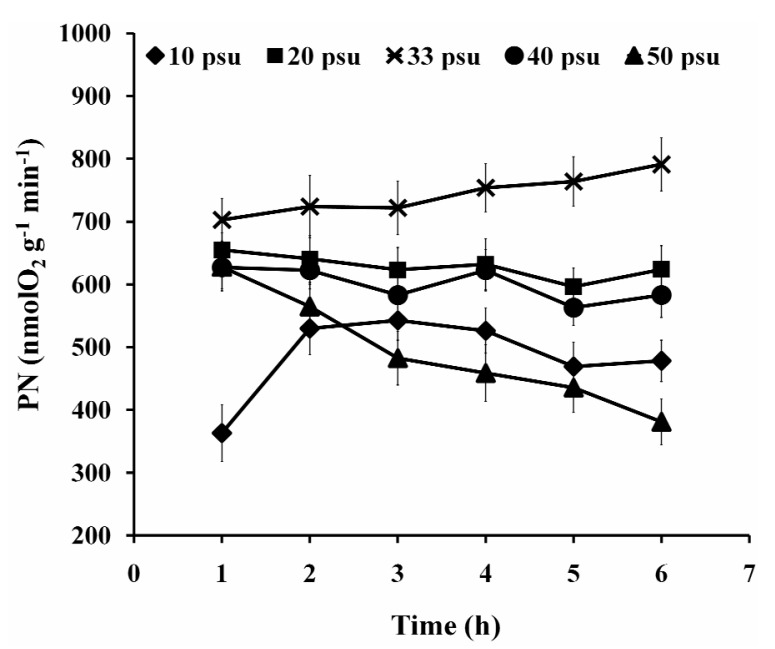

Figure 5. PN of seedlings treated with various salinities for up to $6 \mathrm{~h}$.

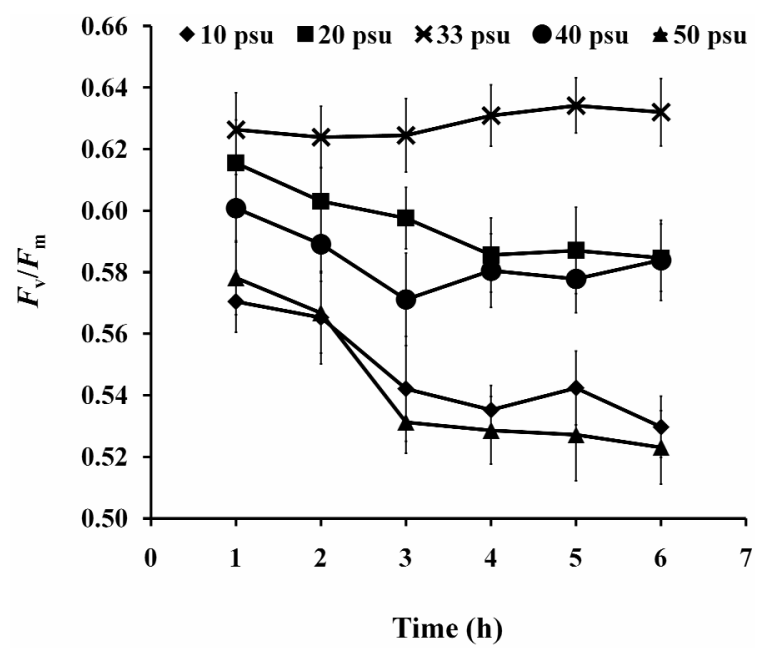

Figure 6. $F_{v} / F_{m}$ of seedlings treated with various salinities for up to $6 \mathrm{~h}$. 


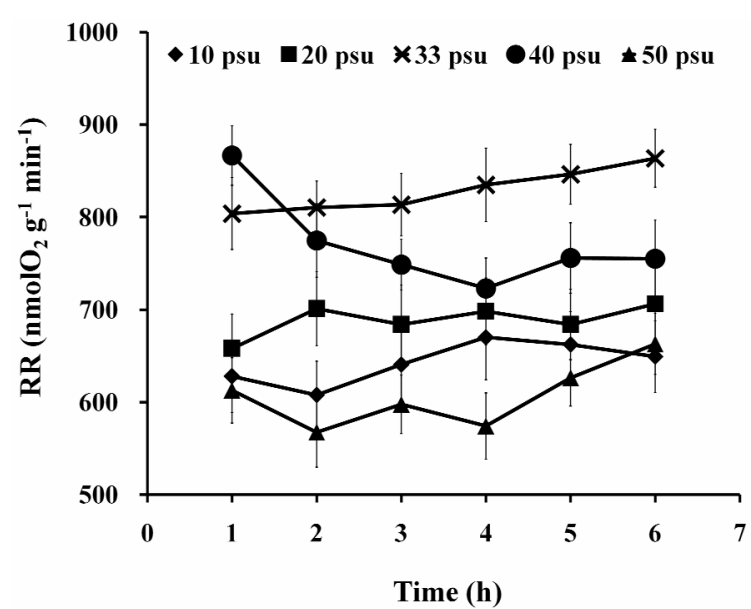

Figure 7. RR of seedlings treated with various salinities for up to $6 \mathrm{~h}$.

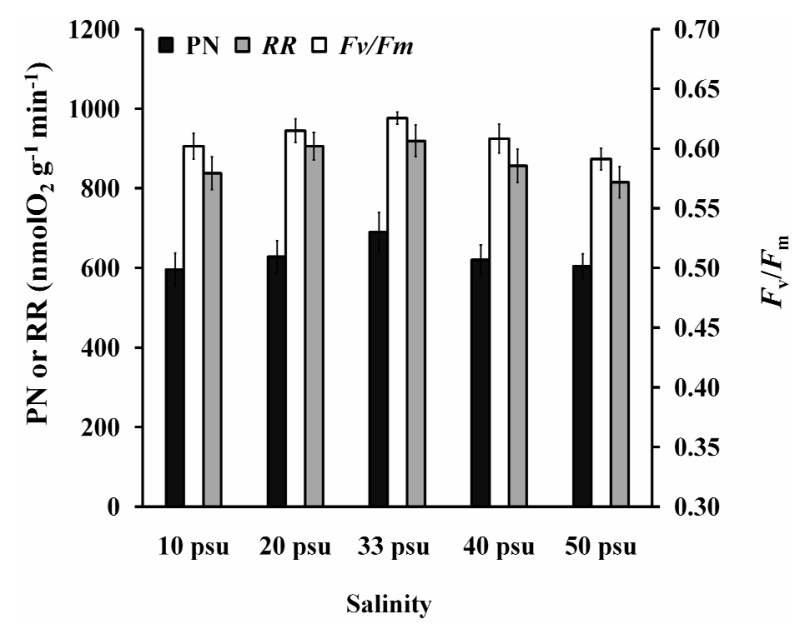

Figure 8. PN, RR, and $F_{v} / F_{m}$ of seedlings after $24 \mathrm{~h}$ recovery.

ergy by pigments or photochemically reactive proteins. Therefore, the slow increase in PN in young seedlings during the initial $4 \mathrm{~d}$ postfertilization may indicate their low content of pigments or photochemically reactive proteins. Such condition may also indicate that these proteins were less developed at this stage. The water depth or light transmission of the workshop ceiling should be adjusted according to different light intensities to achieve the most rapid growth in seedlings. Rapid seedling growth in workplaces will be beneficial for their early transfer to the sea, which may contribute to better seedling growth. Early transfer allows the seedlings to grow in a suitable seawater temperature and an abundant outdoor space.

Low or high temperatures can result in poor growth of seaweeds. Enzymes that catalyze photosynthesis receive less energy at low temperatures, resulting in slow photosynthesis. This idea is supported by the result of this study that PN of S. thunbergii seedlings was significantly reduced at $10^{\circ} \mathrm{C}$. As the temperature increases, enzymes receive more energy, thereby increasing the PN. However, if the temperature is too high, enzymes begin to lose their structure (denature), resulting in inability to function properly, thereby decreasing PN. S. thunbergii seedlings exposed to high temperatures $\left(\geq 28^{\circ} \mathrm{C}\right)$ demonstrated an outstanding ability to down-regulate photosynthetic activities. This finding was reflected by the extremely low values of PN. This phenomenon may indicate that nearly all of the absorbed light energy, which was not used in photochemistry, was converted efficiently into harmless thermal radiation. The same observation was found for Hizikia fusiformis [28] and S. hornerito [29].

During respiration, energy is released from sugar (glucose) via a series of chemical reactions; some of the energy is lost as heat, some is used by plants in various ways. The low-temperature stress $\left(10^{\circ} \mathrm{C}\right)$ resulted in a drastic fluctuation in RR, increasing at first and then decreasing. This phenomenon may due to the stress response of the seaweed, wherein it needs a large amount of heat, which was produced by rapid increase in RR, to resist the low temperature. However, constant low temperature may inhibit respiratory enzymes, resulting in low activity of photosynthetic enzymes and weakening of the material supply for respiration, thereby reducing RR.

Several studies on salinity tolerance mechanism of marine algae have been conducted, and one of the major findings is that $\mathrm{Na}^{+}$-ATPase is the most important factor for salinity resistance among algae $[33,34]$. Short-term highor low-salinity shock had significant effect on PN and RR of $S$. thunbergii seedlings, specifically at 10 and 50 psu. Light-capture and reaction center complexes of the photo-reaction-system have been reported to be injured or partially degraded by salinity stress [35]. However, in the present study, PN and RR returned to normal level after $24 \mathrm{~h}$ of recovery period, which demonstrated a powerful ion-transport system in the seedlings. Algal cells were observed to need more energy at high salinities [36]. The RR for 40 psu treatment was greater than that of the control within $1 \mathrm{~h}$ treatment, which indicated more energy production in S. thunbergii seedlings for short-term salinity resistance. However, the RR decreased gradually after $1 \mathrm{~h}$, which may be due to the passivation of respiretory enzymes. The RR for 50 psu treatment was low throughout the experiment, which indicated that the respiratory enzymes of the seaweed may be maintained in passivation at such high salinity. The stress-recovery capability of $S$. thunbergii seedlings was found to be similar to other cultivated brown algal species, such as $\mathrm{Hi}$ zikia fusiformis [28] and S. hornerito [29]. The findings in the present study contribute in determining the opti- 
mum conditions for seedling rearing, as well as in protecting the $S$. thunbergii seedlings, which are sensitive to osmotic pressure, when various methods are employed to remove various undesirable epiphytic algae and invertebrate larvae for aquaculture management.

\section{Conclusion}

In conclusion, this study provided essential information on the photosynthetic characteristics of $S$. thunbergii seedlings and their abilities to tolerate salinity stress. The LSP of germlings was also investigated. The results provided reference for the control and management of environmental factors affecting the artificial breeding of $S$. thunbergii.

\section{Acknowledgements}

This research is supported by the $863 \mathrm{Hi}$-Tech Research and Development Program of China (no. 2006AA10A416; no. 2012AA10A413) and the National Special Research Fund for Non-Profit Sector of China (Agriculture) (no. 200903030).

\section{REFERENCES}

[1] J. Tsukidate, "Studies on the Regenerative Ability of the Brown Algae, Sargassum muticum (Yendo) Fensholt and Sargassum tortile C. Agardh," Hydrobiologia, Vol. 22, 1984, pp. 393-397. http://dx.doi.org/10.1007/BF00027708

[2] E. X. Zhang, L. J. Yu and X. Xiao, "Studies on Physiological Activity and Biochemistry of Alcohol Extracts from Sargassum thunbergii," Chinese Journal of Marine Drugs, Vol. 13, No. 3, 1994, pp. 1-10. (In Chinese with English abstract).

[3] F. P. Padilha, F. P. Franca and A. C. Costa, "The Use of Waste Biomass of Sargassum sp. for the Biosorption of Copper from Simulated Semiconductor Effluents," Bioresource Technology, Vol. 96, No. 13, 2005, pp. 1511-1517. http://dx.doi.org/10.1016/j.biortech.2004.11.009

[4] H. G. Wu, C. Yu, Z. A. Yao, W. E. Zhang, L. Y. Shi and B. M. Feng, "Analysis of the Nutrient Component in Sargassum thunbergii," Journal of Dalian University, Vol. 29, No. 3, 2008, pp. 84-86. (In Chinese with English abstract)

[5] Z. Y. Liu, X. Q. Sun and S. L. Fan, "Current Difficulties Encountered and Developmental Strategies of Stichopus japonicus aquaculture," Feed Industry, Vol. 27, No. 22, 2006, pp. 28-30. (In Chinese with English abstract)

[6] Z. G. Zhao, F. J. Zhao, J. T. Yao, J. M. Lu, P. O. J. Ang and D. L. Duan, "Early Development of Germlings of Sargassum thunbergii (Fucales, Phaeophyta) under Laboratory Conditions," Journal of Applied Phycology, Vol. 20, No. 5, 2008, pp. 925-931.

http://dx.doi.org/10.1007/s10811-008-9311-y

[7] U. Isamu, "Ecological Studies of Sargassum thunbergii
(Mertens) O. Kuntze in Maizuru Bay, Japan Sea," Journal of Plant Research, Vol. 87, No. 4, 1974, pp. 285-292.

[8] C. H. Koh, Y. Kim and S. G. Kang, "Size Distribution, Growth and Production of Sargassum thunbergii in an Intertidal Zone of Padori, West Coast of Korea," Hydrobiologia, Vol. 260-261, No. 1, 1993, pp. 207-214. http://dx.doi.org/10.1007/BF00049021

[9] K. S. Shao, N. Gong, J. X. Wang, D. C. Li and Z. M. Gao, "Study on Population Ecology of Sargassum thunbergii," Marine Environmental Research, Vol. 29, No. 3, 2010, pp. 332-336. (In Chinese with English abstract)

[10] F. J. Zhao, X. L. Wang, J. D. Liu and D. L. Duan, "Population Genetic Structure of Sargassum thunbergii (Fucales, Phaeophyta) Detected by RAPD and ISSR Markers," Journal of Applied Phycology, Vol. 19, No. 5, 2007, pp. 409-416. http://dx.doi.org/10.1007/s10811-006-9147-2

[11] X. H. Yi, S. G. Li, P. He, H. S. Hou and L. M. Wang, "AFLP Analysis of Genetic Diversity in Six Wild Populations of Sargassum thunbergii," Journal of Fishery Sciences of China, Vol. 17, No. 5, 2010, pp. 922-929. (In Chinese with English abstract)

[12] M. Wang, S. G. Li, H. S. Hou and L. M. Wang, "Genetic Structure of Wild Sargassum thunbergii Populations along Dalian Coast: An ISSR Analysis," Chinese Journal of Ecology, Vol. 29, No. 6, 2010, pp. 1181-1186. (In Chinese with English abstract)

[13] W. Liu, M. Z. Li, H. Y. Wu, D. M. Zhan and G. Ding, "Population Genetic Diversity of sargassum thunbergii in the Coast of China," Oceanologia et Limnologia Sinica, Vol. 42, No. 4, 2011, pp. 608-611. (In Chinese with English abstract)

[14] F. J. Wang, X. T. Sun and F. Li, "Studies on Sexual Reproduction and Seedling-Rearing of Sargassum thunbergii," Marine Fisheries Research, Vol. 27, No. 5, 2006, pp. 1-6. (In Chinese with English abstract)

[15] M. Z. Li, G. Ding, D. M. Zhan, B. Yu, W. Liu and H. Y. $\mathrm{Wu}$, "A Method for Early Production of Large-Size Sargassum thunbergii Seedling in North China," Marine Fisheries Research, Vol. 30, No. 5, 2009, pp. 75-82. (In Chinese with English abstract)

[16] X. T. Sun, F. J. Wang, W. J. Wang, H. T. Jiang, Y. M. Wang, T. Y. Tang and S. Y. Li, "Large Scale Breeding of Sargassum thunbergii Based on Sexual Reproduction," Progress in Fishery Sciences, Vol. 31, No. 3, 2010, pp. 84-91. (In Chinese with English abstract)

[17] Q. S. Zhang, Y. Z. Tang, S. K. Liu, S. B. Zhang and Z. C. Lu, "Zygote-Derived Seedling Production of Sargassum thunbergii: Focus on Two Frequently Experienced Constraints in Tank Culture of Seaweed," Journal of Applied Phycology, Vol. 24, No. 4, 2012, pp. 707-714. http://dx.doi.org/10.1007/s10811-011-9689-9

[18] K. S. Gao and I. Umezaki, "Comparative Photosynthetic Capacities of the Leaves of Upper and Lower Parts of Sargassum Plants," Botanica Marina, Vol. 31, 1988, pp. 231-236. http://dx.doi.org/10.1515/botm.1988.31.3.231

[19] K. S. Gao and I. Umezaki, "Comparative Studies of Photosynthesis in Different Parts of Sargassum thunbergii," Japanese Journal of Phycology, Vol. 37, 1989, pp. 7-16. 
http://mel.xmu.edu.cn/upload_paper/201155110109-0uw SvX.pdf

[20] K. S. Gao and I. Umezaki, "Studies on Diurnal Photosynthetic Performance of Sargassum thunbergii I. Changes in Photosynthetic under Natrual Sunlight," Japanese Journal of Phycology, Vol. 37, 1989, pp. 89-98. http://mel.xmu.edu.cn/upload paper/201155110109-Gef M51.pdf

[21] K. S. Gao and I. Umezaki, "Studies on Diurnal Photosynthetic Performance of Sargassum thunbergii II. Explanation of Diurnal Photosynthesis Patterns from Examinations in the Laboratory," Japanese Journal of Phycology, Vol. 37, 1989, pp. 99-104.

http://mel.xmu.edu.cn/upload paper/201155110109-eVE RbP.PDF

[22] K. S. Gao and H. Nakahara, "Effects of Nutrients on the Photosynthesis of Sargassum thunbergii," Botanica Marina, Vol. 33, 1990, 375-383. http://dx.doi.org/10.1515/botm.1990.33.5.375

[23] K. S. Gao, "Effects of Seawater Current Speed on the Photosynthetic Oxygen Evolution of Sargassum thunbergii (Phaeophyta)," Japanese Journal of Phycology, Vol. 39, 1991, pp. 291-293. (in Japanese)

[24] Z. R. Liang, F. J. Wang, X. T. Sun, W. J. Wang, C. L. Ding and T. Li, "Effects of Environment Factors on Young Seedlings of Sargassum thunbergii by Chlorophyll Fluorescence Method," Journal of Fisheries Chinese, Vol. 35, No. 8, 2011, pp. 1225-1232. (In Chinese with English abstract)

[25] S. H. Chu, Q. S. Zhang, S. K. Liu, Y. Z. Tang, S. B. Zhang, Z. C. Lu and Y. Q. Yu, "Tolerance of Sargassum thunbergii Germlings to Thermal, Osmotic and desiccation Stress," Aquatic Botany, Vol. 96, No. 1, 2012, pp. 1-6. http://dx.doi.org/10.1016/j.aquabot.2011.09.002

[26] S. H. Chu, Q. S. Zhang, Y. Z. Tang, S. B. Zhang, Z. C. Lu and Y. Q. Yu, "High Tolerance to Fluctuating Salinity Allows Sargassum thunbergii Germlings to Survive and Grow in Artificial Habitat of Full Immersion in Intertidal Zone," Journal of the Faculty of Applied Biological Science, Vol. 412, 2012, pp. 66-71. http://dx.doi.org/10.1016/j.jembe.2011.10.025

[27] C. S. Lobban, "Seaweed Ecology and Physiology," Cambridge University Press, Cambridge, 1994, p. 3. http://dx.doi.org/10.1017/CBO9780511626210

[28] S. J. Pang, Z. H. Zhang, H. J. Zhao and J. Z. Sun, "Cultivation of the Brown Alga Hizikia fusiformis (Harvey) Okamura: Stress Resistance of Artificially Raised Young
Seedlings Revealed by Chlorophyll Fluorescence Measurement," Journal of Applied Phycology, Vol. 19, No. 5, 2007, pp. 557-565.

http://dx.doi.org/10.1007/s10811-007-9170-y

[29] Y. R. Zhang, F. Liu, T. F. Shan and S. J. Pang, "Stress Resistance of Young Seedlings of Sargassum hornerito a Variety of Temperatures, Irradiances and Salinities Revealed by Chlorophyll Fluorescence Measurements," South China Fisheries Science, Vol. 5, No. 2, 2009, pp. 1-9. (In Chinese with English abstract)

[30] J. X. Zou, Y. Q. Li, Y. X. Liu, T. W. Zhang and Y. M. Wang, "The Biological Characteristic and Technique of Raft Culture of Sargassum thunbergii," Shandong Fisheries, Vol. 22, No. 3, 2005, pp. 25-29. (In Chinese with English abstract)

[31] K. Maxwell and G. N. Johnson, "Chlorophyll Fluorescence-A Practical Guide," Journal of Experimental Botany, Vol. 51, No. 345, 2000, pp. 659-668. http://dx.doi.org/10.1093/jexbot/51.345.659

[32] H. H. Kobayakawa and K. Imai, "Optimum Dark Adaptation Period for Evaluating the Maximum Quantum Efficiency of Photosystem II in Ozone-Exposed Rice Leaves," American Journal of Plant Sciences, Vol. 4, No. 9, 2013, pp. 1750-1757. http://dx.doi.org/10.4236/ajps.2013.49215

[33] Y. U. Balnokin, L. Popova and H. Gimmler, "Further Evidence for an ATP-Driven Sodium Pump in the Marine Alga Tetraselmis (Platymonas) viridi," Journal of Plant Physiology, Vol. 150, No. 3, 1997, pp. 264-270. http://dx.doi.org/10.1016/S0176-1617(97)80118-6

[34] R. Serrano, J. M. Mulet, G. Rios, J. A. Marquez, I. F. de Larrinoa, M. Leube, I. Mendizabal, A. Pascual-Ahuir, M. Proft, R. Ros and C. Montesinos, "A Glimpse of the Mechanisms of Ion Homeostasis during Salt Stress," Journal of Experimental Botany, Vol. 50, 1999, pp. 1023-1036. http://jxb.oxfordjournals.org/content/50/Special_Issue/10 23.full.pdf

[35] Y. Liang, L. X. Feng, H. Y. Tian and C. L. Yin, "Effects of Salt Stress on the Growth and Chlorophyll Fluorescence of Pyramidomonas sp," Periodical of Ocean University of China, Vol. 36, No. 5, 2006, pp. 726-732. (In Chinese with English abstract)

[36] Y. Kuwada and Y. Ohta, "Effect of Salinity on Hydrogen Production and Growth of Lyngbya sp.," Journal of the Faculty of Applied Biological Science, Vol. 30, No. 1, 1994, pp. 13-18. 